\title{
Pregnancy and low back pain
}

\author{
Jennifer Sabino $\cdot$ Jonathan N. Grauer
}

Published online: 26 February 2008

(C) Humana Press 2008

\begin{abstract}
Back pain is ubiquitous in today's society and is particularly common during pregnancy. There are multiple factors contributing to these symptoms during pregnancy including pelvic changes as well as alterations to loading. Potential imaging modalities are limited during pregnancy due to the desire to limit ionizing radiation exposure to the fetus. Treatments are generally conservative, exercise-based interventions and alternative modalities may also be considered. Low back pain associated with pregnancy does generally resolve postpartum.
\end{abstract}

\section{Keywords Spine $\cdot$ Prengancy}

\section{Introduction}

Back pain is a common complaint of pregnant women. This is generally characterized as axial or para-sagittal discomfort in the lower lumbar region and is musculoskeletal in nature. This can be due to a combination of mechanical, hormonal, circulatory, and psychosocial factors. Treatment options are often poor, as the cause of back pain is not always fully understood. Furthermore, treatments that are available usually have a low success rate and consist mainly of life style adjustments and bed rest.

Discomfort in this region may also be contributed to changes in the posterior pelvic region, particularly the sacroiliac joints which undergo changes during pregnancy

J. Sabino · J. N. Grauer $(\square)$

Department of Orthopaedics and Rehabilitation, Yale University School of Medicine, P.O. Box 208071, New Haven, CT 065208071, USA

e-mail: jonathan.grauer@yale.edu and/or stretch direct stretch of intrapelvic structures. This can manifest itself in the lumbar region and/or radiate to the buttocks and posterior thighs. Unlike radiculopathy, posterior pelvic pain usually does not extend beyond the knees. The classic description of pain felt by most women is usually a result of symptoms of both types of low back pain, lumbar and pelvic.

Such discomfort can have a substantial impact on life during pregnancy and may be of variable intensity and duration. Fortunately, in most cases, low back pain resolves itself quickly after partum and does not cause any lasting issues. However, if discomfort is persistent or not of classic presentation, less common causes such as infection and preterm labor must be considered expeditiously to avoid serious consequences.

\section{Incidence}

Back pain can affect women of child bearing age whether pregnant or not. Approximately $70 \%$ of women will report low back pain at some point in their lives [1]. However, during pregnancy alone, the incidence of back pain is reported by $50-80 \%$ of women $[2,3]$. One-third of pregnant women claim that low back pain is a significant problem [4]. In a study by Stapleton et al. $61.8 \%$ of women who reported low back pain during pregnancy claimed the pain was at least moderately severe, $9 \%$ claimed they were completely disabled by pain [5].

This discomfort most commonly starts between the fifth and seventh month of pregnancy [2]. Morgen et al. reported a mean gestation age at start of pain of 22.1 weeks. However, in this study up to $20 \%$ of women claimed that pain started as early as 16 weeks with some claiming pain within the first month [3]. 
Women with previous lumbar problems or chronic back pain conditions are more likely to develop back pain during pregnancy, with pain occurring twice as often as in those with no prior complaints. They are also more likely to have severe and long lasting pain [6]. Along those same lines, women who experience back pain during one pregnancy have an $85 \%$ chance of experiencing back pain during a subsequent pregnancy [7].

Activity is also related to the onset of back pain during pregnancy $[3,8]$. A sedentary lifestyle increases risk of back pain compared to patients who engage in a more active lifestyle. Nonetheless, patients who have occupations described as 'mostly active' and 'physically demanding' also have a higher risk of developing pain during pregnancy suggesting that extremes of activity are probably not ideal.

Increased body mass index (BMI) may be a risk factor but study results are conflicting. Orvieto et al. found that BMI was significantly higher in those who experience pain compared to those who did not [9]. These results agree with those found by Mogren et al. who found a mean pre and end BMI of 24.57 and 30.10, respectively, in those who had low back pain compared to BMIs of 23.30 and 28.56 in those who did not [3]. However, Mens et al. found no significant difference between BMI before pregnancy in those with back pain and the general population [7]. Younger age and multiple parity also increase the incidence of back pain $[3,10]$.

Associated symptoms include stiffness and limited motion in the back or legs. Pain and associated symptoms may be constant or may only occur in certain positions or after extended activity. Approximately one-third of patients report that pain increases as the day goes on while another one-third report that the pain worsens during the night and often disturbed sleep [2].

Approximately $10 \%$ of women claim that it prevented them from working [11] and more than $80 \%$ report that it affects their daily routine including housework, childrearing, and job performance [7]. Norén et al. report back pain as the leading cause of sick leave during pregnancy in Scandinavian countries, with an estimated cost of $\$ 2.5$ billion in 1990 [12].

\section{Etiology}

Low back pain in pregnancy is generally ascribed to the many changes in load and body mechanics that occur during the carrying of a child. It is normal to gain between 20 and 40 pounds during pregnancy. This clearly shifts the body's center of gravity anteriorly and increase the moment arm of forces applied to the lumbar spine. Studies suggest that an anterior shift is associated with pubic symphysis problems. Furthermore, postural changes may be implemented to balance the anterior shift, leading to lordosis, and increase in the natural inward curvature of the spine, further increasing stress on the lower back [13].

The intervertebral discs respond to axial loading by expelling fluid, resulting in decreased height and an overall compression of the spine [14]. Rodacki et al. showed that the spines of pregnant women with low back pain compress more after activity than pregnant women without back pain and those who are not pregnant, 4.57, 4.23, and $3.99 \mathrm{~mm}$, respectively. Pregnant women with low back pain also take longer to recover from activity related compression [15].

The abdominal muscles also stretch to accommodate the expanding uterus. As they stretch, they lose their ability to perform the function of maintaining body posture, causing the lower back to support the majority of the increased weight of the torso. Studies comparing pregnant women enrolled in an exercise program designed to address core strength, flexibility, and muscular endurance, particularly abdominal strength, with those involved in no exercise program, demonstrated a decrease in postural changes and severity of pain in the exercise group [16].

A significant portion of women first experience pain during the first trimester, when mechanical changes do not yet play a significant role in the etiology of pain [3]. This suggests that some pain may be secondary to hormonal changes rather than physical stresses. Hormonal changes during pregnancy also cause inflammation and pain in the back. For example, some studies have found back pain to correlate with increased levels of relaxin which are produced during pregnancy [17] even though others have not $[18,19]$. It has been suggested that the hormone relaxin increases 10-fold in concentration during pregnancy. As the structures of the pelvis and lower spine soften and become more pliant, discomfort may result particularly not only in the sacroiliac joint but also generalized over the entire lower back.

Another theory has been put forward that low back pain during pregnancy, especially pain that worsens at night and is severe enough to wake the patient up, is the result of venous engorgement in the pelvis. The expanding uterus presses on the vena cava, particularly at night when the patient is lying down. This combined with the increased fluid volume from fluid retention during pregnancy leads to venous congestion and hypoxia in the pelvic and lumbar spine. Fast et al. correlated this condition to the low back pain experienced at night in patients with congestive heart failure [20].

Sciatica, caused by herniation or bulging of an intervertebral disc resulting in nerve compression is often thought to be the cause of low back pain. Associated symptoms of pregnancy, like leg pain and faulty bladder control, can point to this diagnosis. However, during pregnancy this is very unlikely and only presents in about $1 \%$ of pregnant women. 
Back pain can also be caused by all of the normal factors associated with back pain in the non-pregnant population. Factors such as degenerative disc disease, malignancy, and infection are all potential causes. Pregnancy related problems may also develop such as preterm labor and pregnancy induced osteoporosis. These causes present a more serious problem that can significantly endanger the health of the mother and fetus if not dealt with quickly.

\section{Diagnosis}

Diagnosis of low back pain is usually based on symptoms because there are few tests available to aid in diagnosis because of fear of harming the fetus. Evaluation of low back pain during pregnancy is difficult because the pain is subjective and usually the result of a combination of problems. Pain is most often measured on a horizontal visual analogue scale from 1 to 100 with anchors at 'no pain' and worst pain imaginable.

Classic mobility models cannot be applied to pregnant women because their mobility pattern and expectations are different from the general population. Disability as the result of pain is often measured using the Quebec back pain disability scale. While this scale is used primarily to measure disability from nondescript low back pain not related to pregnancy, it can be adapted to use for pregnancy related pain [21-23]. Several studies have attempted to develop a system to evaluate the extent and effect of pain specifically during and after pregnancy. Van De Pol et al. developed the Pregnancy Mobility Index (PMI) to assess the ability to do normal household activities on a scale from 'no problems performing this task' to 'performing this task is impossible or only possible with the aid of others.' The PMI was found to be a valid assessment of mobility during and after pregnancy [24].

Physical exam can distinguish posterior pelvic pain from lumbar pain by several maneuvers. The posterior pelvic pain provoking test, standing on one leg, and Patrick Fabere test elicit pelvic pain. Each test manipulates the patients' legs to put pressure on the pelvic joints. Palpation over soft tissue of the sacroiliac, pubic symphysis, and gluteal regions distinguish pelvic pain from tenderness over the back above the waist. Studies show that both methods are effective in diagnosing posterior pelvic pain and distinguishing among the various causative syndromes; although pain provocation tests are more reliable than topography/palpation tests [25].

When the source of the problem is difficult to determine by history and physical alone, imaging techniques are available for consideration. The amount of radiation or Grays depends on the type of imaging technique used and the area of the mother exposed. The effect of absorbed radiation depends on gestational age of the fetus. At 2 8 weeks, a dose of less than 10 cGy poses no increased risk of abnormalities, while the risk of anomalies increases $1 \%$ per $10 \mathrm{cGy}$ increase [26]. From 9 to 15 weeks, risks are similar and increase with dose. After 15 weeks there is a measurable increase in the risk of cancer with an exposure as low as $1 \mathrm{cGy}$ [27].

The fetus is exposed to virtually no radiation when radiographs of the extremities, head, or chest are done with proper shielding. However, the fetus does absorb a moderate to high amount of radiation when imaging the lumbar spine. The mean fetal exposure for a conventional lumbar spine radiograph is $1.7 \mathrm{mGy}$ with a maximum dose of $10 \mathrm{mGy}$ while the mean and maximum dose for computed tomography is 2.4 and 8.6, respectively [26]. Magnetic resonance imaging is the preferred technique for severe low back pain that is not relieved with more conservative therapy during pregnancy. Uroradiologic procedure occasionally preformed for hydronephrosis in pregnant women result in a mean uterine dose of .4 mGy [28].

\section{Treatment}

Most women consider back discomfort as an inevitable part of pregnancy and do not seek treatment from a health care professional. Only about $50 \%$ of women visit a physician for low back or pelvic pain. Women who rate their pain higher on a VAS are more likely to see a physician. Of the women who saw a physician, $70 \%$ were treated. The majority of women treated report more than one type of treatment [8].

The majority of treatment strategies center on prevention because treatment late into the pregnancy is often difficult to implement. When treatment is sought; conservative management of low back pain is preferred during pregnancy for obvious reasons, although such treatments typically do not have a high incidence of success. Treatment options include physiotherapy, transcutaneous nerve stimulation, pharmacological treatment, acupuncture or chiropractic treatment, and stabilization belts. Proper posture is essential for the relief of low back pain. While instruction may be enough to alleviate the pain, braces are available to insure proper body positioning.

Exercise before and early in pregnancy can strengthen abdominal, back, and pelvic muscles, which improves posture and allows increased weight bearing ability. Low intensity exercise can also alleviate pain once it develops. Exercise during the second half of pregnancy significantly decreases pain following a three time a week 12 week program [29]. Pelvic tilts are particularly effective in relieving lumbar pain. Knee pull, straight leg raising, curl up, lateral straight leg raising, and the Kegel exercises are 
also successful in relieving low back pain in pregnant women. Water aerobics is another recommended strategy that has shown to reduce pain and, as a result, the need for sick leave in women with lumbar pain during pregnancy [30].

Back-pain-reducing programs involving exercise and education are often implemented early in pregnancy to combat occurrence or increased intensity of pain. Some studies show that such interventional therapy reduces intensity and anxiety, decreases the amount of sick leave taken, and prevents prolonged postpartum back pain [11, 31] and recurrence at 6-year follow-up [32]. However, other studies contradict these findings. Dumas et al. found no significant difference in the prevalence of back pain or resulting functional limitations in pregnant women enrolled in an interventional exercise class and those who remained sedentary [16].

Studies have shown that complementary and alternative medicine therapies can be an effective means of decreasing back pain during pregnancy. One-third of the population of the United States use such alternative therapies, the majority of whom are women of childbearing age [33]. Consequently, it is no surprise that alternative therapies are a popular option for pain relief. The most popular therapies include massage, acupuncture, relaxation, yoga, and chiropractic procedures. Similarly, over $90 \%$ of prenatal health care providers would recommend some kind of nonpharmalogical treatment, including some alternative therapies. Midwives (93\%) are more likely to recommend alternative treatments than physicians $(64 \%)$ or prenatal nurse educators $(57 \%)$ [34].

Support belts and corsets are another means to support the back. Pelvic girdle belts are used to press together the articular surfaces of the sacroiliac joints to provide stability and decrease laxity in the pelvis. Application of a pelvic belt in a high position was found to significantly decrease pelvic laxity using Doppler imaging of vibration in the prone position [35]. Studies have shown that the use of pelvic belts have been effective in relieving pain $[7,36]$. A pelvic belt is often the most prevalent therapy, although women do not rate it as the most effective therapy available [8].

Opoid medications can be prescribed for severe pain. Care must be taken to limit the dose to avoid opoid withdrawal in the newborn. In one case, physicians used an epidural administration instead of an oral route to minimize daily dosage in a woman with severe back pain due to multiple herniated discs [37].

Simple home remedies such as heating pads and over the counter pain medication can also ease pain. Acetaminophen is an acceptable over the counter medication to relieve pain during pregnancy while aspirin and ibuprofen are not. Muscle relaxants can also be prescribed.
Comfortable shoes without heels reduce symptoms and allow for more motility.

\section{Outcomes}

Persistent postpartum back pain, either recurrent or continuous, is significantly linked to symptoms during pregnancy. While most low back pain will relieve itself within 6 months of partum, some will cause lasting problems. Mogren et al. found that of 464 subjects approximately $40 \%$ had pain 6 months post-pregnancy. The majority $(36.2 \%)$ had recurrent pain while only $6.9 \%$ complained of continuous pain [38]. In a 3-year follow up study, $20 \%$ of women who reported back pain during pregnancy claimed that they still experienced pain [39].

A history of back pain, younger age, especially younger than 20 years, joint hyper-mobility, and an earlier onset of pain are associated risk factors for prolonged symptoms. A body mass index greater than 25 pre-pregnancy, endpregnancy and 6 months after pregnancy is also a predisposing condition for continuing low back pain [13, 40]. However, in a retrospective study only $10-25 \%$ of women with chronic back pain claim that their first incidence of pain occurred during pregnancy, indicating that persistent problems after pregnancy are often linked to previous conditions [1, 36, 41].

\section{Summary}

Low back is a common problem for all women but there is an increased incidence of back pain associated with pregnancy. The most common complaint of pregnant women, low back pain can be the normal result of a multitude of mechanical, hormonal, and vascular changes associated with pregnancy. However, while usually regarded with a laissez-faire attitude, back pain during pregnancy should be taken seriously by patients and physicians. A number of serious pathological processes could be involved endangering both mother and fetus.

Treatment options for low back pain consist mostly of postural education and rest. Physical therapy and fitness programs are available to prevent back pain and alleviate pain if it already exists. Alternative therapies are becoming more and more popular in the pregnant population as a safe means to combat pain. More vigorous treatment is available for serious problems. However, most women use an at home approach with support belts, heating pads, and postural pillows. Whatever the cause, low back pain is a significant distressing factor to pregnant women and should not be ignored as a normal consequence of becoming pregnant. 


\section{References}

1. Svensson HO, Andersson GB, Hagstad A, Jansson PO. The relationship of low-back pain to pregnancy and gynecologic factors. Spine 1990;15:371-5.

2. Fast A, Shapiro D, Ducommun EJ, Friedmann LW, Bouklas T, Floman Y. Low back pain in pregnancy. Spine 1987;12:368-71.

3. Mogren IM, Pohjanen AI. Low back pain and pelvic pain during pregnancy: prevalence and risk factors. Spine 2005;30(8):98391.

4. Östgaard HC, Andersson GB, Karlsson K. Prevalence of back pain in pregnancy. Spine 1991;16:549-52.

5. Stapleton DB, MacLennan AH, Kristiansson P. The prevalence of recalled low back pain during and after pregnancy: a south Australian population study. Aust N Z J Obstet Gynaecol 2002;42(5):482-5.

6. Östgaard HC, Andersson GB. Previous back pain and risk of developing back pain in a future pregnancy. Spine 1991;16:432-6.

7. Mens JMA, Vleeming A, Stoeckart R, Stam HJ, Snijders CJ. Understanding peripartum pelvic pain. Implications of a patient survey. Spine 1996;21(11):1363-70.

8. Mogren IM. Previous physical activity decreases the risk of low back pain and pelvic pain during pregnancy. Scand J Public Health 2005;33(4):300-6.

9. Orvieto R, Achiron A, Ben-Rafael Z, Gelernter I, Achiron R. Low back pain of pregnancy. Acta Obstet Gynecol Scand 1994; 73(3):209-14

10. Kristiansson P, Svärdsudd K, von Schoultz B. Back pain during pregnancy. Spine 1996;6:702-9.

11. Berg G, Hammar M, Moller-Neilsen J, Linden U, Thorblad J. Low back pain during pregnancy. Obstet Gynecol 1988;71:71-5.

12. Norén L, Östgaard S, Neilsen T, Östgaard HC. Reduction of sick leave for lumbar back and posterior pelvic pain in pregnancy. Spine 1997;22(18):2157-60.

13. Sandler SE. The management of low back pain in pregnancy. Manual Ther 1996;1:178-85.

14. Botsford DJ, Esses SI, Oglivie-Harris DJ. In vivo indurnal variation in intervertebral volume and morphology. Spine 1994;19:935-40.

15. Rodacki CL, Fowler NE, Rodacki AL, Birch K. Stature loss and recovery in pregnant women with and without low back pain. Arch Phys Med and Rehab 2003;84(4):507-12.

16. Dumas GA, Reid JG, Wolfe LA, Griffin MP, McGrath MJ. Exercise, posture, and back pain during pregnancy, Part 1. Exercise and back pain. Clin Biomech 1995;10(2):104-9.

17. MacLennan AH, Nicolson R, Green RC, Bath M. Serum relaxin and pelvic pain of pregnancy. Lancet 1986;ii:243-5.

18. Albert H, Godskesen M, Westergaard JG, Chard T, Gunn L. Circulating levels of relaxin are normal in pregnant women with pelvic pain. Eur J Obstet Gynecol Reprod Biol 1997;74:19-22.

19. Hansen A, Jensen DV, Larsen E, Wilken-Jensen C, Pedersen LK. Relaxin is not related to symptom-giving pelvic girdle relaxation in pregnant women. Acta Obstet Gynecol Scand 1996;75:245-9.

20. Fast A, Weiss L, Parich S, Hertz G. Night backache in pregnancyhypothetical pathophysiological mechanisms. Am J Phys Med Rehab 1989;68:227-9.

21. Damen L, Buyruk HM, Güler-Uysal F, et al. Pelvic pain during pregnancy is associated with asymmetric laxity of the sacroiliac joints. Acta Obstet Gynecol Scand 2001;80:1019-24.

22. Mens JMA, Vleeming A, Snijders CJ, Stam HJ, Ginai AZ. The active straight leg raising test and mobility of pelvic joints. Eur Spine J 1999;8:468-73.
23. Mens JMA, Vleeming A, Snijders CJ, Ronchetti I, Ginai AZ, Stam HJ. Responsiveness of outcome measurements in rehabilitation of patients with posterior pelvic pain since pregnancy. Spine 2002;27:1110-5.

24. Van De Pol G, De Leeuw JRJ, Van Brummen HJ, Bruinse HW, Heintz APM, et al. The pregnancy mobility index: a mobility scale during and after pregnancy. Acta Obstet Gynecol Scand 2006;85(6):647-56.

25. Albert H, Godskesen M, Westergaard J. Evaluation of clinical tests used in classification procedures in pregnancy-related pelvic joint pain. Eur Spine J 2000;9:161-6.

26. Timins J. Pregnancy and medical radiation: part I. J Women's Imaging 2002;4(1):31-2.

27. Doll R, Wakeford R. Risk of childhood cancer from fetal irradiation. Br J Radiol 1997;70:130-9.

28. Hellawell GO, Cowan NC, Holt SJ, Mutch SJ. A radiation perspective for treating loin pain in pregnancy by double-pigtail stents. BJU Int 2002;90(9):801-8.

29. Garshasbi A, Faghih Zadeh S. The effect of exercise on the intensity of low back pain in pregnant women. Spine 2005;30(8):983-91.

30. Granath AB, Hellgren MSE, Gunnarsson RK. Water aerobics reduces sick leave due to low back pain during pregnancy. JOGNN 2006;35(4):465-71.

31. Kihlstrand M, Stenman B, Nilsson S, Axelesson D. Water-gymnastics reduced the intensity of back/low back pain in pregnant women. Acta Obstet Gynecol Scand 1999;7:180-5.

32. Östgaard HC, Zetherström G, Roos-Hansson E. Regression of back and posterior pelvic pain after pregnancy. Spine 1997;22(24):2945-50.

33. Eisenberg DM, Davis RB, Ettner SL, Appel S, Wilkey S, Van Rompay M, Kessler RC. Trends in alternative medicine use in the United States, 1990-1997: results of a follow-up national survey. JAMA 1998;280:1569-75.

34. Wang SM, DeZinno P, Fermo L, William K, Caldwell-Andrews AA, Bravemen F, Kain ZN. Complementary and alternative medicine for low-back pain in pregnancy: a cross-sectional survey. J Alt Comp Medicine 2005;11(3):459-64.

35. Mens JMA, Damen L, Snijders CJ, Stam HJ. The mechanical effect of a pelvic belt in patients with pregnancy-related pelvic pain. Clin Biomech 2006;21(2):122-7.

36. Biering-Sorensen F. A prospective study of low back pain in a general population. I. Occurrence, recurrence and aetiology. Scand J Rehabil Med 1983;15:71-79.

37. Sabatowski R, Radbruch L, Grond S, Göhring UJ. Treatment of severe low back pain with opiods during pregnancy in a patient with incomplete tetraplegia. Acta Anaesthesiol Scand 2000;44(3):348-50.

38. Mogren IM. BMI, pain and hyper-mobility are determinants of long-term outcome for women with low back pain and pelvic pain during pregnancy. Eur Spine J 2006;15(7):1093-102.

39. Norén L, Östgaard S, Johansson G, Östgaard HC. Lumbar back and posterior pelvic pain during pregnancy: a 3-year follow-up. Eur Spine J 2002;11:267-71.

40. Breen TW, Ransil BJ, Groves PA, Oriol NE. Factors associated with back pain after childbirth. Anesthesiology 1994;81:29-34.

41. Biering-Sorensen F. Low back trouble in a general population of 30-, 40-, 50-, and 60-year-old men and women. Study design, representativeness and basic results. Dan Med Bull 1982;29:28999. 